\title{
Ethylene glycol (EG)-based nanofluids as a coolant for automotive radiator
}

\author{
Winifred Nduku Mutuku*
}

\author{
${ }^{*}$ Correspondence: \\ mutukuwinnie@gmail.com \\ Department of Mathematics, \\ Kenyatta University, P. O. \\ Box 43844-001 00, Nairobi, \\ Kenya
}

\begin{abstract}
In this paper, the cooling capabilities of an ethylene glycol (EG)-based nanofluid containing three different types of nanoparticles: copper oxide (CuO), aluminium oxide $\left(\mathrm{Al}_{2} \mathrm{O}_{3}\right)$, and titanium dioxide $\left(\mathrm{TiO}_{2}\right)$ are investigated. Nanofluids have enhanced thermophysical properties, hence they can be used in a plethora mechanical and engineering applications such as nanofluid coolant: electronics cooling, vehicle cooling, transformer cooling, computers cooling and electronic devices cooling. A model depicting the vertical fluid flow in a radiator is formulated. Using appropriate similarity transformation and shooting quadrature coupled with Runge-Kutta-Fehlberg integration scheme, the model boundary value problem is tackled numerically. A parametric study of the entire flow regime is carried out to illustrate the effects of the pertinent parameters on the velocity, temperature, skin friction coefficient and the local Nusselt number. It is clear that CuO-EG nanofluids lead to a rapid decrease of temperature at the boundary layer.
\end{abstract}

Keywords: Nanofluid, Coolant, Convective heating, Radiator

\section{Background}

Convectional heat transfer fluids such as water, minerals oil and ethylene glycol play an important role in many industrial sectors including power generation, chemical production, air-conditioning, transportation and microelectronics. Although various techniques have been applied to enhance their heat transfer capabilities, their performance is often limited by their low thermal conductivities which obstruct the performance enhancement and compactness of heat exchangers. With the rising demand of modern technology for process intensification and device miniaturization, there was a need to develop new types of fluids that are more effective in terms of heat exchange performance. To achieve this, it has been recently proposed to disperse small amounts of nanometer-sized (10-50 nm) solid particles (nanoparticles) in base fluids, resulting in what is commonly known as nanofluids. The term nanofluid was coined by Choi [1] who was working with the group at the Argonne National Laboratory (ANL), USA, in 1995. The nanoparticles used are ultrafine; therefore, nanofluids appear to behave more like a single-phase fluid than a solid-liquid mixture. The commonly used materials for nanoparticles are metals ( $\mathrm{Al}, \mathrm{Cu}, \mathrm{Ag}, \mathrm{Au}, \mathrm{Fe}$ ), nonmetals (graphite, carbon nanotubes), oxides ceramics $\left(\mathrm{Al}_{2} \mathrm{O}_{3}, \mathrm{CuO}, \mathrm{TiO}_{2}, \mathrm{SiO}_{2}\right)$, carbides $(\mathrm{SiC})$, nitrides (AiN, $\mathrm{SiN}$ ), layered $\left(\mathrm{Al}+\mathrm{Al}_{2} \mathrm{O}_{3}, \mathrm{Cu}+\mathrm{C}\right), \mathrm{PCM}$ and functionalized nanoparticles. The base fluid is usually

(c) 2016 The Author(s). This article is distributed under the terms of the Creative Commons Attribution 4.0 International License (http://creativecommons.org/licenses/by/4.0/), which permits unrestricted use, distribution, and reproduction in any medium, provided you give appropriate credit to the original author(s) and the source, provide a link to the Creative Commons license, and indicate if changes were made. 
a conductive fluid, such as water (or other coolants), oil (and other lubricants), polymer solutions, bio-fluids and other common fluids, such as paraffin. Investigations have shown that nanofluids possess enhanced thermophysical properties such as thermal conductivity, thermal diffusivity, viscosity and convective heat transfer coefficients compared to those of base fluids like oil or water [2-7]. Owing to their enhanced thermophysical properties, nanofluids have numerous industrial, engineering and bio-medical applications such as heat transfer applications: industrial cooling, smart fluids; nanofluid coolant: vehicle cooling, electronics cooling; medical applications: magnetic drug targeting and nanocryosurgery [8].

In recent years, heat transfer has received many engineering applications such as heat exchanger, piping system, solar collectors and electric conductors. Some of these applications depend on natural convection for heat transfer mechanism, while others depend on forced convection for heat removal in the systems. However, it is quite evident that appropriate convective heat transfer fluids are necessary. The use of nanofluids as coolants would allow for smaller sized and better positioning of the radiators [9]. Owing to the fact that there would be less fluid due to the higher efficiency, coolant pumps could be shrunk and truck engines could be operated at higher temperatures allowing for more horsepower while still meeting stringent emission standards. Future engines designed using nanofluids cooling properties will run at more optimal temperatures allowing for increased power output. With a nanofluid engine, components would be smaller and weigh less allowing for less fuel consumption, saving consumers money and resulting in fewer emissions for a cleaner environment. Singh et al. [10], researchers at Argonne National Laboratory assessing the applications of nanofluids for transportation, determined that the use of high-thermal conductive nanofluids in radiators can lead to a reduction in the frontal area of the radiator by up to $10 \%$. This new aerodynamic automotive design which minimises the aerodynamics drag not only leads to fuel saving of up to $5 \%$ but also reduces emissions as well. The use of nanofluid also leads to a reduction of friction and wear, reducing parasitic losses, operation of components such as pumps and compressors and hence more than $6 \%$ fuel savings. It can be concluded that the use of nanofluids will enhance the efficiency and economic performance of car engines, as well as greatly influence the structural design of automotives, such as smaller and lighter engine radiators cooled by a nanofluids which can be placed elsewhere in the vehicle as opposed to the front of the car. By reducing the size and repositioning the radiator, a reduction in weight and wind resistance could enable greater fuel efficiency and subsequently lower exhaust emissions.

A specific component for heat transfer mechanism in automobile engine block is the radiator. It is a form of heat exchanger used for cooling the internal combustion engines, mainly in automobiles and in piston engine of aircrafts, locomotives (trains), motorcycles and stationary generating plants. It circulates liquid through the engine block where it is heated, then pumped through the radiator where it loses heat to the atmosphere via fins and lastly returns to the engine block. In this regard, there is a need to improve the technical parts of a car engine to attain high efficiency, to achieve optimal fuel consumption, to increase working life and to reduce pollution. Reducing the weight of a car with optimal design of its radiator is a necessity. Adding fins and fan is one way to increase the rate of cooling in automobile radiators in which a larger surface area for heat transfer is 
created and air convection is utilised to enhance heat transfer. However, with the advent of nanofluids, the rate of heat transfer in radiators can be improved by the employment of a coolant fluid with enhanced thermal conductivity. The most commonly used coolant fluids are water or ethylene glycol whose thermal conductivity coefficient is very low. However, as earlier pointed out, their heat transfer performance is often limited by their low thermal conductivities which obstruct the performance enhancement and compactness of heat exchangers. Wang and Mujumdar [11] investigated heat transfer characteristics of nanofluids and recommended further research on the main parameters affecting their heat transfer properties. Das et al. [12] investigated utilisation of nanofluids in heat exchangers and realised a significant possibility for use in cooling and related technologies. Thermal conductivity of metallic liquids is much greater than that of non-metallic liquids. It is then expected that the thermal conductivities of the fluids with metallic nanoparticles should be significantly higher. Nguyen et al. [13] used $\mathrm{Al}_{2} \mathrm{O}_{3} /$ water nanofluids in cooling system of electrical devices and they observed a lot of improvement of heat transfer coefficients for a low level volume fraction of nanoparticles. Leong et al. [14] investigated the performance of ethylene glycol/copper nanofluids and reported an enhanced heat transfer rate. Research undertaken by [15-19] has shown that dispersing nanoparticles of copper $(\mathrm{Cu})$, copper oxide $(\mathrm{CuO})$, aluminium oxide $\left(\mathrm{Al}_{2} \mathrm{O}_{3}\right)$, titanium oxide $\left(\mathrm{TiO}_{2}\right)$ lead to an anomalously increased thermal physical properties of ethylene glycol-based nanofluids.

On the other hand, magnetohydrodynamic (MHD) boundary layer flow of an electrically conducting viscous fluid with a convective surface boundary condition is frequently encountered in many industrial and technological applications such as extrusion of plastics in the manufacture of Rayon and Nylon, the cooling of reactors, purification of crude oil, textile industry, polymer technology, and metallurgy. According to Mutuku and Makinde [20], nanofluids are highly susceptible to the effects of magnetic field compared to conventional base fluid due to the complex interaction of the electrical conductivity of nanoparticles with that of base fluid.

Despite nanofluids' copious applications with regard to heat transfer, it is evident from the literature herein that limited research has focussed on the comparison of the heat transfer enhancement to base fluids due to the presence of different nanoparticles. Also, it is evident that most studies considered water as the base fluid. The motivation of the current study is thus to investigate the thermal performance of nanofluids coolant in a car radiator using ethylene glycol (EG) as a base fluid and employing three nanoparticles: $\mathrm{Al}_{2} \mathrm{O}_{3}, \mathrm{TiO}_{2}$, and $\mathrm{CuO}$. $\mathrm{EG}$ is an organic liquid of low viscosity and low volatility, which is completely miscible with water, thus it can be used as a base fluid on its own or mixed with water to form EG-water base fluid. The effects of magnetic field strength on the fluid flow are also investigated. In the subsequent sections, the boundary layer partial differential equations governing the fluid flow are first transformed into a system of nonlinear ordinary differential equations, before being solved numerically using a shooting method coupled with the fourth-order Runge-Kutta-Fehlberg integration scheme. A graphical representation of the pertinent parameters on the flow field and heat transfer characteristics are displayed and thoroughly discussed. 


\section{Problem formulation}

A steady, incompressible, laminar, two-dimensional $(x, y)$ boundary layer flow of an electrically conducting ethylene glycol-based nanofluid past a convectively heated vertical semi-infinite flat plate under the influence of a transversely imposed magnetic field is considered (see Fig. 1). The nanofluids contain three different types of nanoparticles: $\mathrm{CuO}, \mathrm{Al}_{2} \mathrm{O}_{3}$, and $\mathrm{TiO}_{2}$. It is assumed that the left side of the plate is heated by convection from a hot fluid at temperature $T_{f}$ with a heat transfer coefficient $h_{f}$ A transverse magnetic field of strength $B_{0}$ is applied parallel to they-axis. There is no applied voltage and the magnetic Reynolds number is small, hence the induced magnetic field and Hall effects are negligible.

Considering the nanofluid as continuous media with thermal equilibrium and no slip occurring between the base fluid and the solid nanoparticles, the governing equations of continuity, momentum and energy balance with Boussinesq approximation for buoyancy term are given as [7]:

$$
\begin{aligned}
& \frac{\partial u}{\partial x}+\frac{\partial v}{\partial y}=0 \\
& u \frac{\partial u}{\partial x}+v \frac{\partial u}{\partial y}=\frac{\mu_{n f}}{\rho_{n f}} \frac{\partial^{2} u}{\partial y^{2}}+\beta_{n f} g\left(T-T_{\infty}\right)-\frac{\sigma_{n f} \beta_{0}^{2} u}{\rho_{n f}} \\
& u \frac{\partial T}{\partial x}+v \frac{\partial T}{\partial y}=\frac{k_{n f}}{\left(\rho c_{p}\right)_{n f}} \frac{\partial^{2} T}{\partial y^{2}}+\frac{\mu_{n f}}{\left(\rho c_{p}\right)_{n f}}\left(\frac{\partial u}{\partial y}\right)^{2}+\frac{\sigma_{n f} B_{0}^{2} u^{2}}{\left(\rho c_{p}\right)_{n f}}
\end{aligned}
$$

where $(u, v)$ are velocity components in the $(x, y)$ directions, respectively, $\rho_{n f}$ is the density of nanofluid, $\mathrm{T}$ is the local temperature, $\mu_{n f}$ is the dynamic viscosity of the fluid, $\mathrm{p}$ is the fluid pressure, $\beta_{n f}$ is the volume expansion coefficient of the fluid, $\mathrm{k}_{\mathrm{nf}}$ is the heat transfer coefficient of nanofluid, $\sigma_{n f}$ is the electrical conductivity of nanofluid, $B_{0}$ is the magnetic field, $g$ is the gravitation vector, $\left(\rho C_{p}\right)_{n f}$ is the heat capacitance and $c_{p}$ is the capacity at constant pressure.

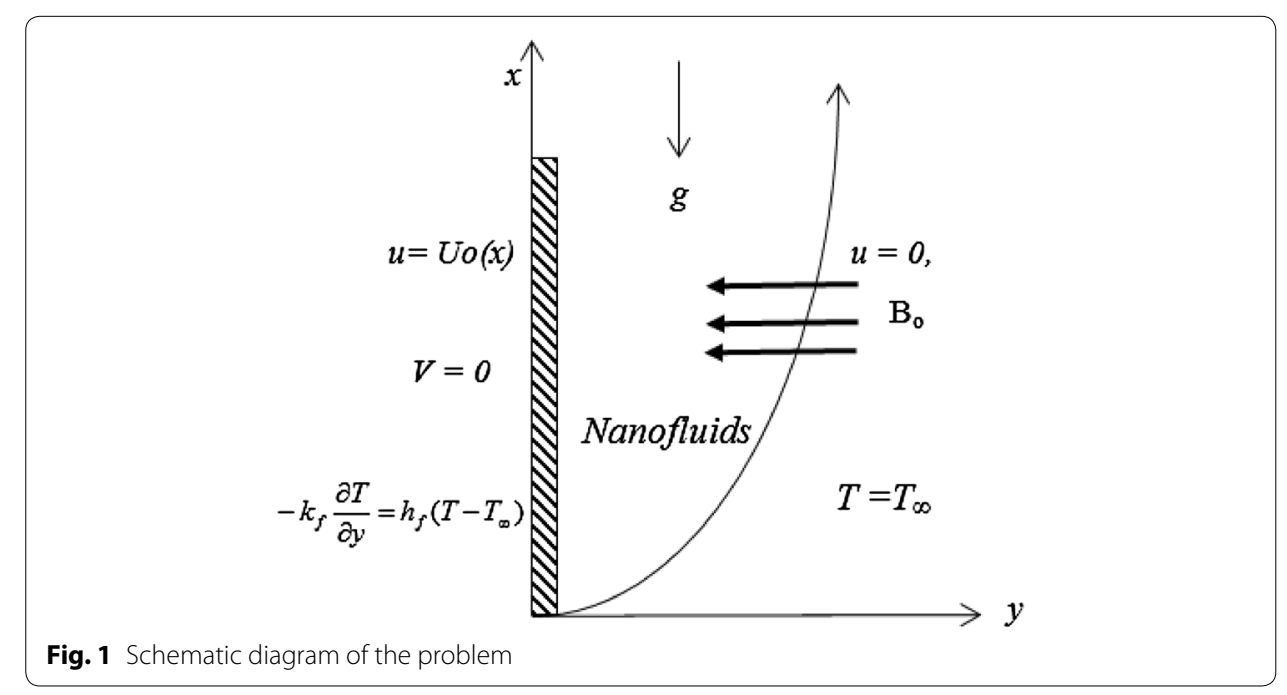


The boundary conditions at the plate surface and at the free stream are expressed as:

$$
\begin{aligned}
u(x, 0) & =U_{0}, \quad \mathrm{v}(x, 0)=0, \quad-k_{n f} \frac{\partial T}{\partial y}(x, 0)=h_{f}\left(T_{f}-T(x, 0)\right), \\
u(x, \infty) & =0, \quad \mathrm{~T}(x, \infty)=T_{\infty},
\end{aligned}
$$

By assuming that the particle concentration is well dispersed and uniformly distributed throughout the system, the effective thermo-physical properties of the mixture can be evaluated using Eq. (5) below. These relations can be used to predict nanofluids physical properties like density, viscosity, thermal conductivity, specific heat and volume expansion at different temperatures and volume fractions (concentrations).

$$
\begin{aligned}
& \mu_{n f}=\frac{\mu_{f}}{(1-\phi)^{2.5}}, \quad \rho_{n f}=(1-\phi) \rho_{f}+\phi \rho_{s}, \quad \beta_{\mathrm{nf}}=(1-\phi) \quad \beta_{f}+\phi \beta_{s} \\
& \frac{k_{n f}}{k_{f}}=\frac{\left(k_{s}+2 k_{f}\right)-2 \phi\left(k_{f}-k_{s}\right)}{\left(k_{s}+2 k_{f}\right)+\phi\left(k_{f}-k_{s}\right)}, \quad\left(\rho c_{p}\right)_{n f}=(1-\phi)\left(\rho c_{p}\right)_{f}+\phi\left(\rho c_{p}\right)_{s}, \\
& \sigma_{n f}=\sigma_{f}\left[1+\frac{3(r-1) \phi}{(r+2)-(r-1) \phi}\right], \quad r=\frac{\sigma_{s}}{\sigma_{f}},
\end{aligned}
$$

where $\phi$ is the nanoparticle volume fraction ( $\phi=0$ correspond to a regular fluid), $\rho_{f}$ and $\rho_{s}$ are the densities of the base fluid and the nanoparticle, respectively, $\beta_{\mathrm{f}}$ and $\beta_{\mathrm{s}}$ are the thermal expansion coefficients of the base fluid and the nanoparticle, respectively, $k_{f}$ and $k_{s}$ are the thermal conductivities of the base fluid and the nanoparticles, respectively, $\left(\rho c_{p}\right)_{f}$ and $\left(\rho c_{p}\right)_{s}$ are the heat capacitance of the base fluid and the nanoparticle, respectively, $\sigma_{s}$ and $\sigma_{f}$ are the electrical conductivities of the base fluid and the nanofluid, respectively.

The stream function $\psi(x, y)$ defined as $u=\frac{\partial \psi}{\partial y}$ and $v=-\frac{\partial \psi}{\partial x}$ satisfies the continuity Eq. (1). To simplify the mathematical analysis of the problem, the following similarity transformations are introduced:

$$
\eta=\left(a / v_{f}\right)^{1 / 2} y, \quad \psi=\left(a v_{f}\right)^{1 / 2} x f(\eta), \quad \theta(\eta)=\frac{T-T_{\infty}}{T_{w}-T_{\infty}}
$$

where $\eta$ is the similarity variable, $f(\eta)$ is the non-dimensional stream function and $\theta(\eta)$ is the non-dimensional temperature. After introducing Eq. (6) into Eqs. (2) and (3), we obtain the following ordinary differential equations:

$$
\begin{aligned}
f^{\prime \prime \prime} & +(1-\phi)^{2.5}\left(1-\phi+\phi \rho_{s} / \rho_{f}\right) f^{\prime \prime}-(1-\phi)^{2.5}\left(1-\phi+\phi \rho_{s} / \rho_{f}\right) f^{\prime 2} \\
& -H a\left[1+\frac{3(r-1) \varphi}{(r+2)-(r-1) \varphi}\right](1-\phi)^{2.5} f^{\prime} \\
& +G r(1-\phi)^{2.5}\left(1-\phi+\phi \beta_{s} / \beta_{f}\right)\left(1-\phi+\phi \rho_{s} / \rho_{f}\right) \theta=0, \\
\theta^{\prime \prime} & +\frac{k_{f}}{k_{n f}} p_{r}\left(1-\phi+\phi\left(\rho c_{p}\right)_{s} /\left(\rho c_{p}\right)_{f}\right) f \theta^{\prime}+\frac{k_{f} E c \operatorname{Pr}}{k_{n f}(1-\phi)^{2.5}}\left(f^{\prime \prime}\right)^{2} \\
& +\left[1+\frac{3(r-1) \varphi}{(r+2)-(r-1) \varphi}\right] \frac{k_{f} H a E c \operatorname{Pr}}{k_{n f}} f^{\prime 2}=0,
\end{aligned}
$$


Subject to the following boundary conditions:

$$
\begin{aligned}
f(0) & =0, \quad f^{\prime}(0)=1, \quad \theta^{\prime}(0)=B i[\theta(0)-1], \\
f^{\prime}(\infty) & =0, \quad \theta^{\prime}(\infty)=0,
\end{aligned}
$$

where primes denote differentiation with respect to $\eta$ and the Hartmann number $\mathrm{Ha}$, Grashof number $G r$, Prandtl number $P r$, Eckert number Ec, and Biot number $B i$ are defined as:

$$
\begin{aligned}
H a & =\frac{\sigma_{f} B_{o}^{2} x}{\rho_{f} U_{o}}, \quad G r=\frac{\beta_{f} g\left(T_{f}-T_{\infty}\right)}{U_{0} a}, \quad E c=\frac{U_{o}^{2}}{C p_{f}\left(T_{f}-T_{\infty}\right)}, \\
B i & =\frac{h_{f}}{k_{f}} \sqrt{\frac{v_{f} x}{U_{o}}}, \quad \operatorname{Pr}=\frac{v_{f}}{\alpha_{f}}
\end{aligned}
$$

For engineering and industrial application purposes, the physical quantities of practical significance in this work are the skin friction coefficient $C_{f}$ and the Nusselt number $\mathrm{Nu}$ defined as:

$$
C_{f}=\frac{\tau_{w}}{\rho_{f} U_{o}^{2}}, \quad N u=\frac{x q_{w}}{k_{f}\left(T_{f}-T_{\infty}\right)},
$$

where $\tau_{w}$ is the skin friction and $q_{w}$ is the surface heat flux given by

$$
\tau_{w}=\left.\mu_{n f} \frac{\partial u}{\partial y}\right|_{y=0}, \quad q_{w}=-\left.k_{n f} \frac{\partial T}{\partial y}\right|_{y=0},
$$

Putting Eqs. (12) into (11), we obtain

$$
\begin{aligned}
C_{f_{x}} & =\operatorname{Re}_{x}^{1 / 2} C_{f}=\frac{1}{(1-\phi)^{2.5}} f^{\prime \prime}(0), \\
N u_{x} & =\operatorname{Re}_{x}^{-1 / 2} N u=-\frac{k_{n f}}{k_{f}} \theta^{\prime}(0),
\end{aligned}
$$

which are the local Skin Friction $C_{f_{x}}$ and local Nusselt number $N u_{x}$, and $\operatorname{Re}=\frac{U_{0} x}{v_{f}}$ is the local Reynolds number.

\section{Numerical procedure}

The set of Eqs. (7)-(8) under the boundary conditions (9) is a coupled nonlinear boundary value problems (BVP) which are solved numerically using a shooting algorithm with a Runge-Kutta-Fehlberg integration scheme. This method involves transforming the equation into a set of initial value problems (IVP) which contain unknown initial values that need to be determined by guessing, after which the fourth-order RungeKutta-Fehlberg iteration scheme is employed to integrate the set of IVPs until the given boundary conditions are satisfied.

We define new variables:

$$
x_{1}=f, \quad x_{2}=f^{\prime}, \quad x_{3}=f^{\prime \prime}, \quad x_{4}=\theta, \quad x_{5}=\theta^{\prime},
$$


This reduces Eqs. (7)-(8) to systems of first-order differential equations:

$$
\begin{aligned}
x_{3}^{\prime}= & H a\left[1+\frac{3(r-1) \varphi}{(r+2)-(r-1) \varphi}\right](1-\phi)^{2.5} x_{2}-(1-\phi)^{2.5}\left(1-\phi+\phi \rho_{s} / \rho_{f}\right) x_{1} x_{3} \\
& -G r(1-\phi)^{2.5}\left(1-\phi+\phi \beta_{s} / \beta_{f}\right)\left(1-\phi+\phi \rho_{s} / \rho_{f}\right) x_{4} \\
& +(1-\phi)^{2.5}\left(1-\phi+\phi \rho_{s} / \rho_{f}\right) x_{2}^{2} \\
x_{5}^{\prime}= & -\frac{k_{f}}{k_{n f}} p_{r}\left(1-\phi+\phi\left(\rho c_{p}\right)_{s} /\left(\rho c_{p}\right)_{f}\right) x_{1} x_{5}-\frac{k_{f} E c \operatorname{Pr}}{k_{n f}(1-\phi)^{2.5}} x_{3}^{2} \\
& -\left[1+\frac{3(r-1) \varphi}{(r+2)-(r-1) \varphi}\right] \frac{k_{f} H a E c \operatorname{Pr}}{k_{n f}} x_{2}^{2}
\end{aligned}
$$

subject to the following initial conditions:

$$
\begin{aligned}
& x_{1}(0)=0, \quad x_{2}(0)=1, \quad x_{5}(0)=B i\left[x_{4}(0)-1\right], \\
& x_{2}(0)=s_{1}, \quad x_{5}(0)=s_{2},
\end{aligned}
$$

In the shooting process, the unknown initial conditions $s_{1}$ and $s_{2}$ in Eq. (17) are assumed and Eqs. (15)-(16) integrated numerically as an initial valued problem to a given terminal point. The accuracy of the assumed missing initial conditions was checked by comparing the calculated value of the dependent variable at the terminal point with its given value there. If differences exist, improved values of the missing initial conditions are obtained and the process repeated. The entire computation procedure is implemented using a program which uses symbolic and computational computer language MAPLE [21]. Being a BVP, the equations are automatically solved by the dsolve command by applying the appropriate algorithm. The present method is unconditionally stable and has been successfully used by Makinde et al. [22] to solve various problem in fluid mechanics and heat transfer. From the process of numerical computation, the fluid velocity, the temperature, the skin friction coefficient and the Nusselt number are presented by $f^{\prime}(\eta), \theta(\eta), f^{\prime \prime}(\eta)$ and $\theta^{\prime}(\eta)$, respectively.

\section{Results and Discussion}

Three different types of nanoparticles, namely, copper oxide $(\mathrm{CuO})$, aluminium oxide $\left(\mathrm{Al}_{2} \mathrm{O}_{3}\right)$, and titanium dioxide $\left(\mathrm{TiO}_{2}\right)$ with ethylene glycol as the base fluid were considered. The results are presented graphically in Figs. 2, 3, 4, 5, 6, 7, 8, 9, 10, 11, 12 and 13, and conclusions are drawn for the flow field taking into consideration their industrial and engineering applications. $H a=0$ corresponds to the absence of magnetic field, and $\phi=0$ is regular fluid. To ascertain the validity of the numerical procedure, the special case of heat transfer in MHD flow of a convectional fluid $(\phi=0)$ over a moving surface is compared with that of Kuznetsov and Nield [23] as shown in Table 1 and a perfect agreement was established. This favourable comparison lends confidence to the numerical results reported subsequently. The thermophysical properties of ethylene-glycol and the nanoparticles are shown in Table 2. 


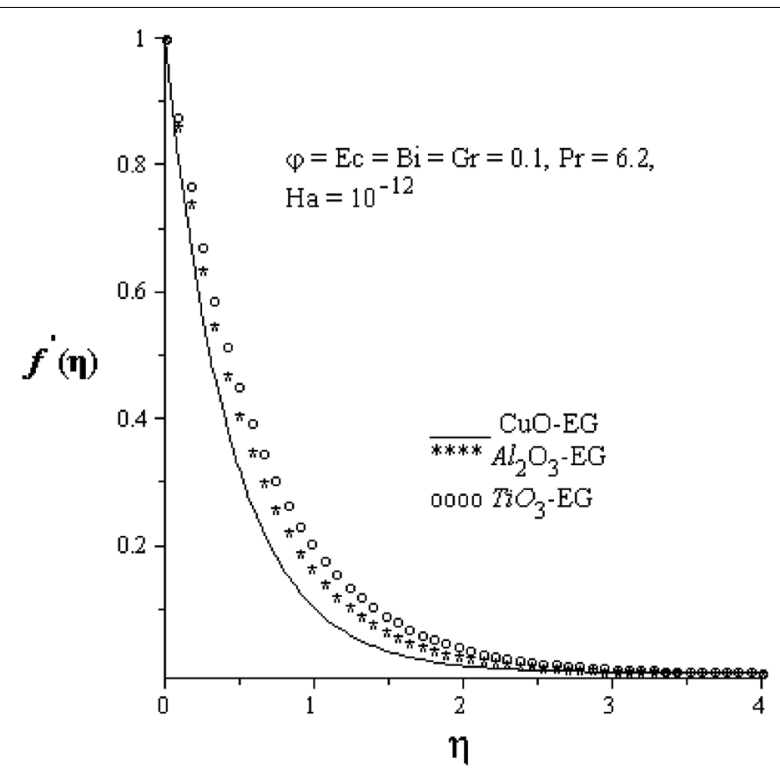

Fig. 2 Velocity profiles for different nanofluids

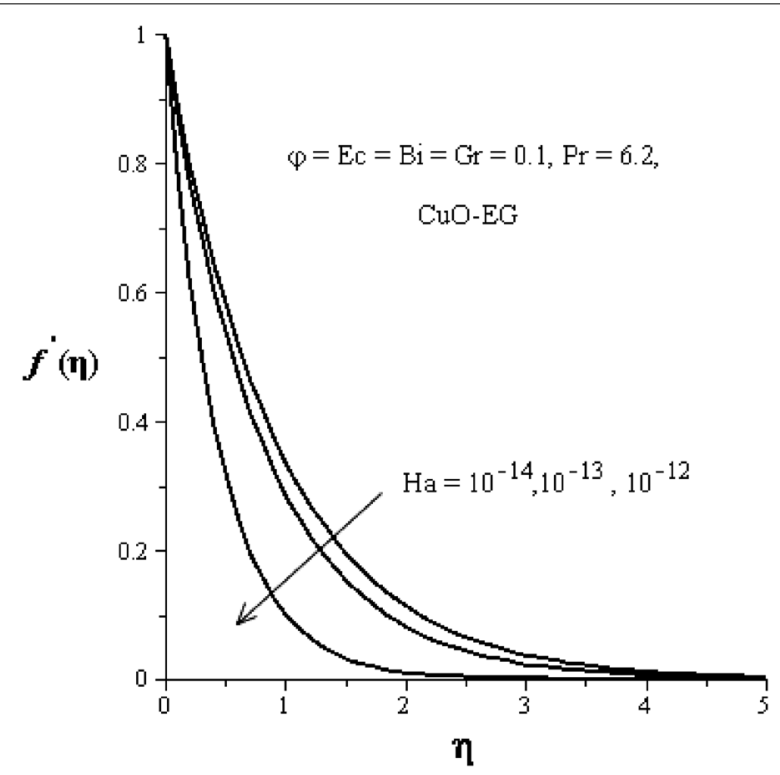

Fig. 3 Velocity profiles with varying $(\mathrm{Ha})$

\section{Dimensionless velocity profiles}

Figures 2, 3 and 4 depict the effects of various physical parameters on the nanofluid velocity profiles. It is noted that for all the pertinent parameters, the velocity is maximum at the moving plate surface but decreases gradually to zero at the free stream far away from the plate surface, thus satisfying the boundary conditions. As shown in Fig. 2, the momentum boundary thickness for CuO-EG nanofluid is thinner compared to the other nanofluids. This is due to the fact that $\mathrm{CuO}$ is more susceptible to the influence of the magnetic field than the rest of the nanoparticles used. Consequently, $\mathrm{CuO}-\mathrm{EG}$ 


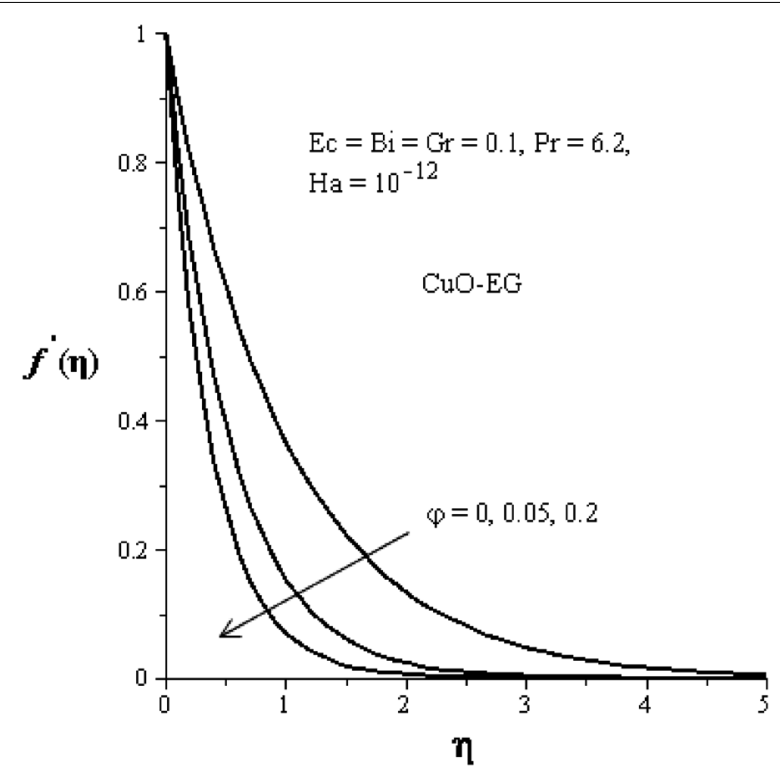

Fig. 4 Velocity profiles with increasing nanoparticles volume fraction

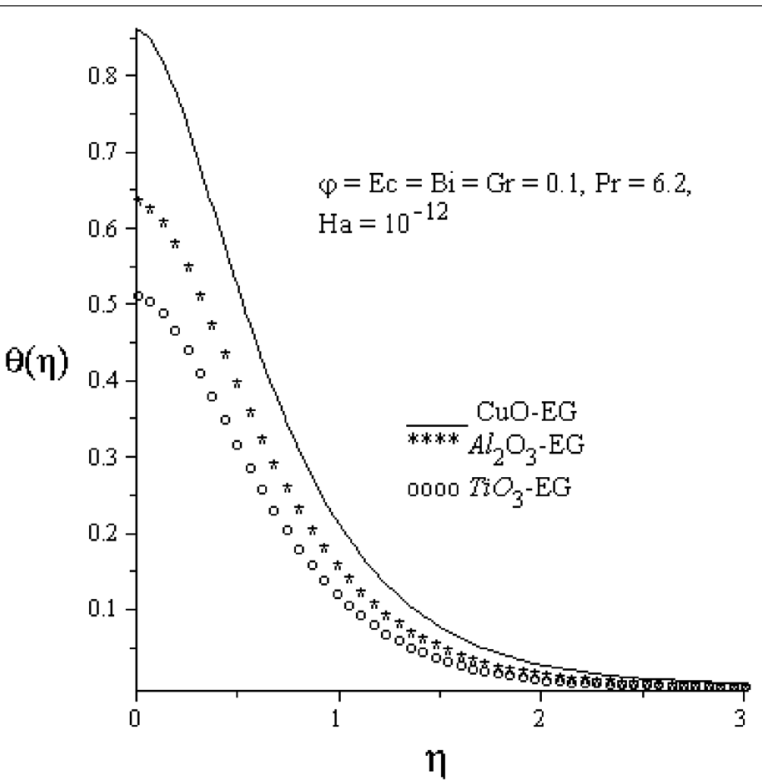

Fig. 5 Temperature profiles for different nanofluids

nanofluid tends to flow closer to the convectively heated plate surface. As expected from theory and as illustrated in Fig. 3, increasing the magnetic parameter $\mathrm{Ha}$ slackens the fluid velocity due to the Lorentz force which results in resistance to the transport phenomena. This retarding force can control the nanofluids velocity which is useful in numerous industrial, engineering and bio-medical applications such as heat transfer applications: industrial cooling, smart fluids; nanofluid coolant: vehicle cooling, electronics cooling; medical applications: magnetic drug targeting and nanocryosurgery. 


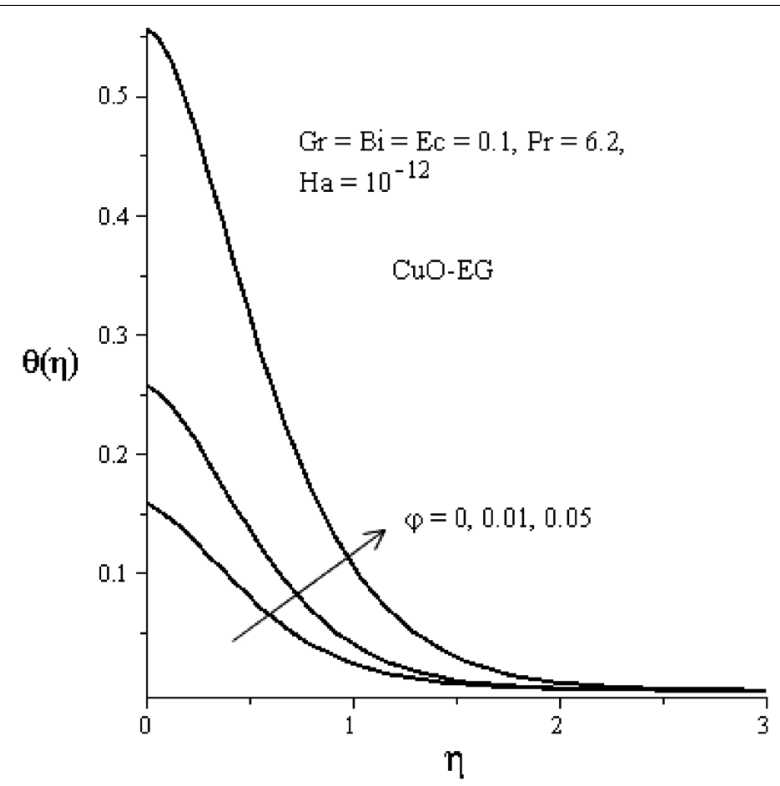

Fig. 6 Temperature profiles with increasing $\varphi$

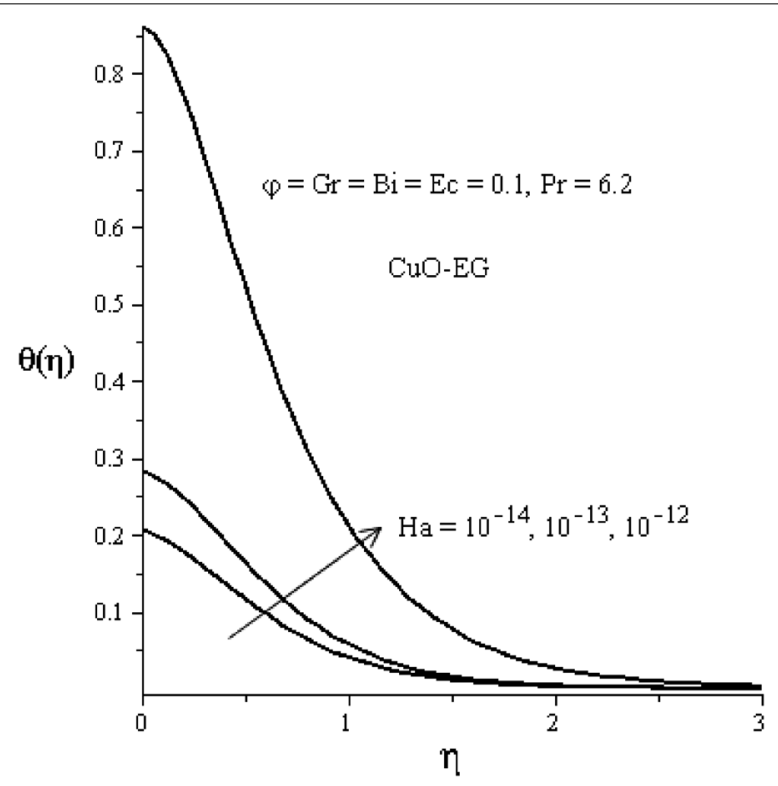

Fig. 7 Temperature profiles with increasing $\mathrm{Ha}$

Similarly, the presence of the nanoparticles increases the viscosity of the base fluid, thus impeding fluid flow as shown in Fig. 4.

\section{Dimensionless temperature profiles}

Figures 5, 6, 7, 8 and 9 show the effects of pertinent parameter on the temperature profile. It is observed that the temperature gradually decreases from a maximum value near the plate surface to zero far away from the plate satisfying the free stream conditions. Figure 6 shows that $\mathrm{CuO}-\mathrm{EG}$ nanofluid thermal boundary layer thickness is greater than 


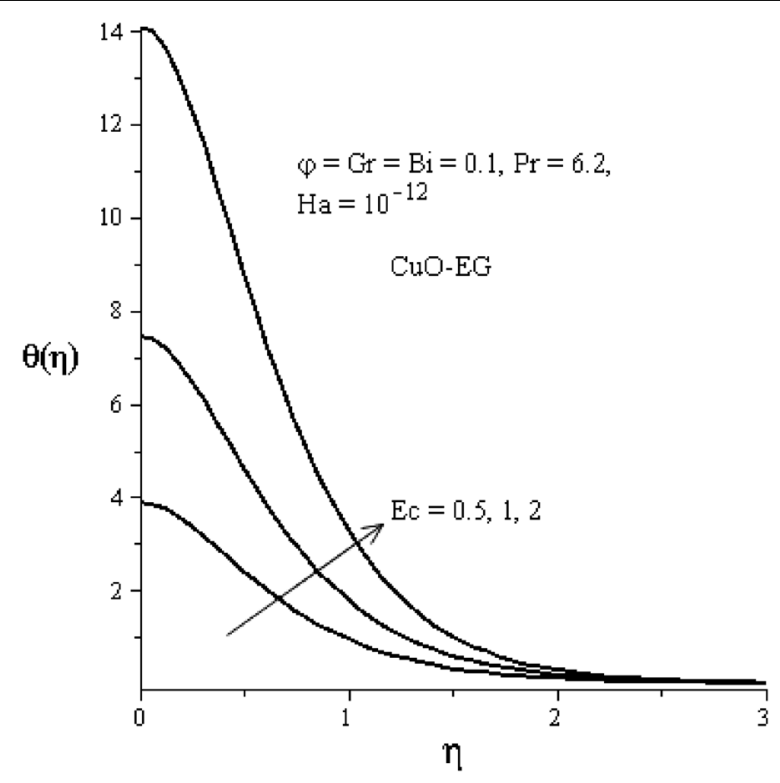

Fig. 8 Temperature profiles with increasing $E c$

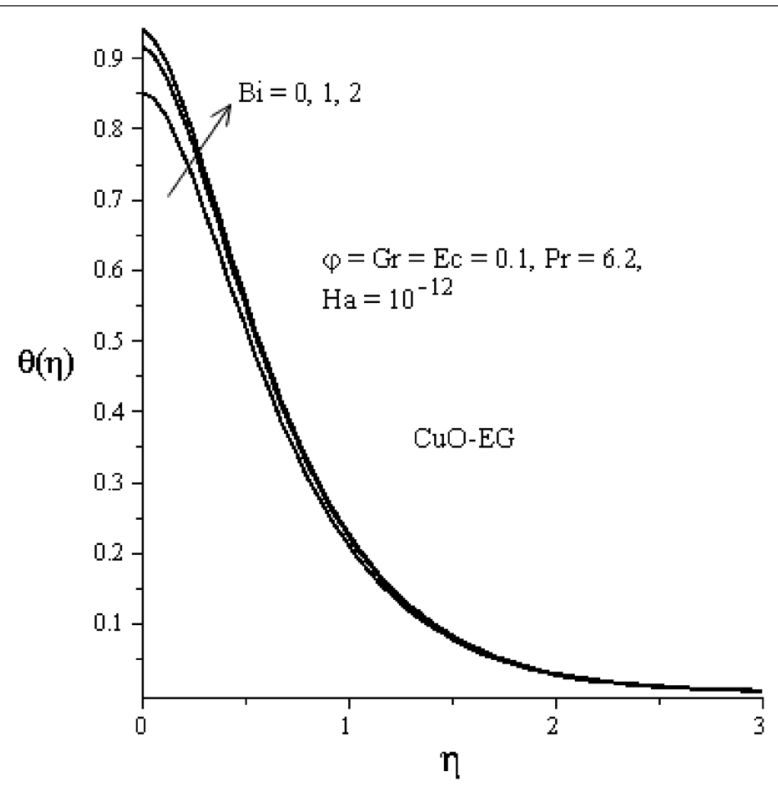

Fig. 9 Temperature profiles with increasing $B i$

that the other two nanofluid as expected. This is in accordance with the earlier observation, since the $\mathrm{CuO}-\mathrm{EG}$ nanofluid tends to absorb more heat from the plate surface owing to its close proximity to the hot surface. The constant collision of the nanoparticles in the base fluid which is associated with Brownian motion as well as the thermophoresis effect has the summative effect of increasing the fluid temperature; thus, as shown in Fig. 6, increasing the nanoparticle volume fraction $\phi$ increases the fluid temperature. In Fig. 7, it is noted that an increase in $\mathrm{Ha}$ leads to an increase in the temperature and, as a result, the thermal boundary layer thickness increases. This is as expected, 


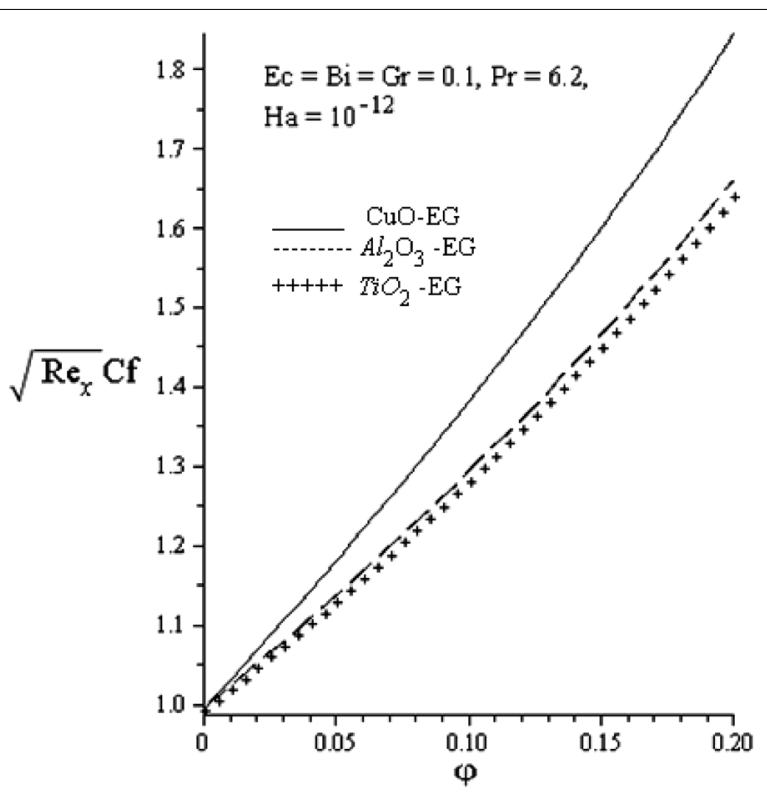

Fig. 10 Skin friction profiles for different nanofluids

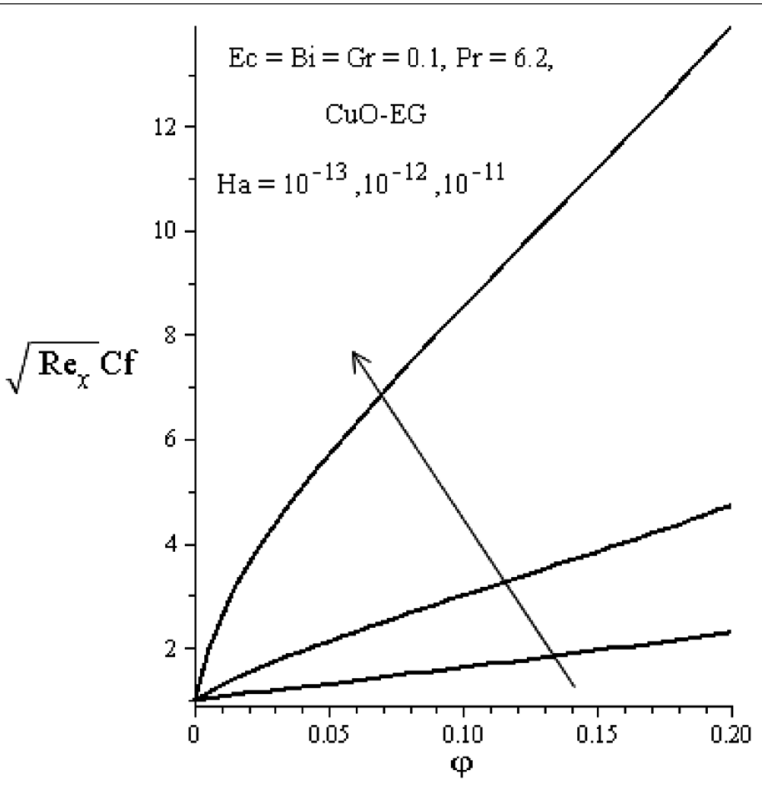

Fig. 11 Skin friction with increasing $\mathrm{Ha}$

since the presence of the magnetic field results in joule heating. The Eckert number $E c$ which is synonymous to viscous dissipation has a similar effect as seen in Fig. 8. Increasing the Biot number $B i$ increases the temperature and the thermal boundary layer thickness, a fact attributed to an increase in the convective heating as shown in Fig. 9.

\section{Effects of parameters variation on the skin friction and Nusselt number}

Figures 10, 11, 12 and 13 illustrate the effects of the various pertinent parameters at the plate surface for both the skin friction coefficient and the local Nusselt number (rate of 


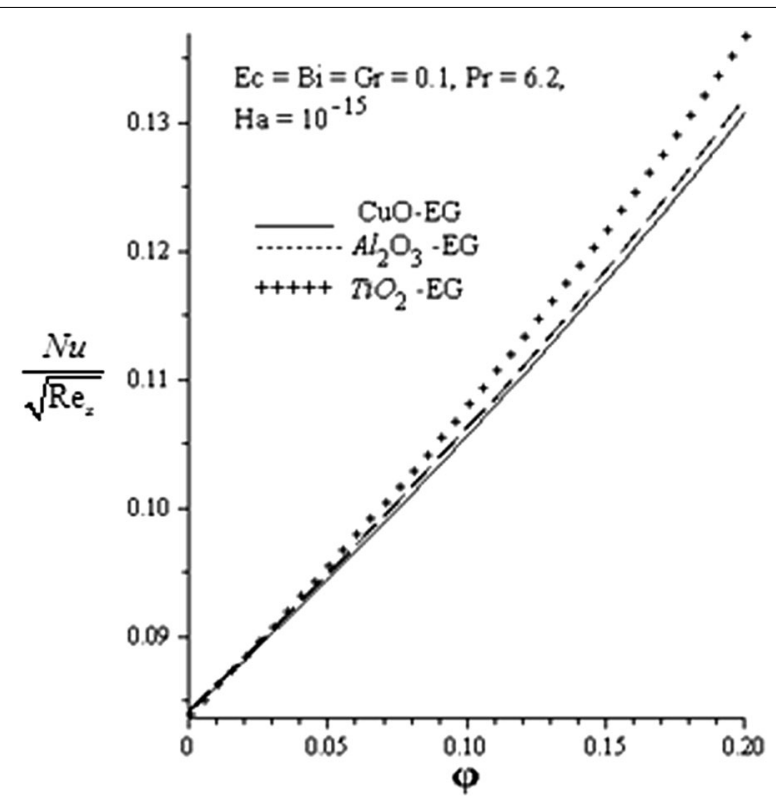

Fig. 12 Nusselt number for different nanofluids

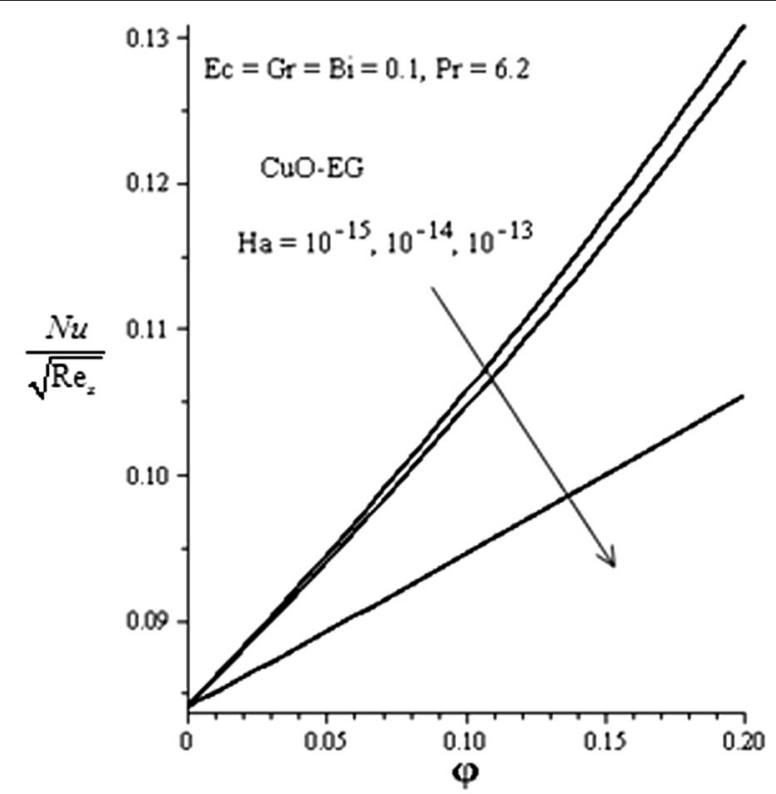

Fig. 13 Nusselt number with increasing $\mathrm{Ha}$

Table 1 Comparison test results of the local Nusselt number $\mathrm{Nu}$ in the limiting case of a regular fluid with no magnetic field for $E C=B i=G r=0.1$

\begin{tabular}{lllll}
\hline Pr & 1 & 10 & 100 & 1000 \\
$\mathrm{Nu}$ (Kuznetsov \& Nield [16]) & 0.401 & 0.463 & 0.481 & 0.484 \\
$\mathrm{Nu}$ (present) & 0.401 & 0.463 & 0.481 & 0.484 \\
\hline
\end{tabular}


Table 2 Thermophysical properties of ethylene glycol and nanoparticles [16, 17]

\begin{tabular}{lllllr}
\hline Materials & $\boldsymbol{\rho}\left(\mathbf{k g} / \mathbf{m}^{\mathbf{3}}\right)$ & $\boldsymbol{c}_{\boldsymbol{p}}(\mathbf{J} / \mathbf{k g K})$ & $\boldsymbol{k}(\mathbf{W} / \mathbf{m K})$ & $\boldsymbol{\beta} \times \mathbf{1 0}^{-\mathbf{5}} \mathbf{( \mathbf { k } ^ { - \mathbf { 1 } } )}$ & $\boldsymbol{\sigma}(\mathbf{S} / \mathbf{m})$ \\
\hline Ethylene-glycol & 1114 & 2415 & 0.252 & 57 & $5.5 \times 10^{-6}$ \\
Copper oxide (CuO) & 6510 & 540 & 18 & 0.85 & $5.96 \times 10^{7}$ \\
Alumina $\left(\mathrm{Al}_{2} \mathrm{O}_{3}\right)$ & 3970 & 765 & 40 & 0.85 & $3.5 \times 10^{7}$ \\
Titania $\left(\mathrm{TiO}_{2}\right)$ & 4250 & 686.2 & 8.9538 & 0.9 & $2.38 \times 10^{6}$ \\
\hline
\end{tabular}

heat transfer). The presence of nanoparticle in the convectional fluid leads to an increase in both the skin friction and the rate of heat transfer as illustrated in Figs. 11 and 13, while, on the other hand, increasing the magnetic field strength $\mathrm{Ha}$ leads to an increase in the skin friction. This is as expected, since the presence of the nanoparticles increases the viscosity of the fluid and thus increased friction at the plate surface. It is clear from the graphical presentations that $\mathrm{CuO}-\mathrm{EG}$ nanofluid exhibits the highest skin friction and the least rate of heat transfer, whereas $\mathrm{TiO}_{2}-\mathrm{EG}$ nanofluid has the least skin friction and the highest rate of heat transfer. This is in accordance with expectation, since the CuO-EG nanofluid moves closer to the plate surface leading to an elevation in the velocity gradient at the plate surface and thus the increased friction at the plate surface. From an engineering and industrial application point of view, $\mathrm{TiO}_{2}-\mathrm{EG}$ nanofluid would make the best coolant owing to the fact that it has the greatest heat transfer at the plate surface while at the same time, it causes less tear and wear to the plate surface owing to the minimal skin friction. Increasing the magnetic strength increases the skin friction, but reduces the rate of heat transfer as shown in Figs. 11 and 13.

\section{Conclusions}

The cooling capabilities of an ethylene-glycol (EG)-based nanofluid containing three different types of nanoparticles: copper oxide $(\mathrm{CuO})$, aluminium oxide $\left(\mathrm{Al}_{2} \mathrm{O}_{3}\right)$, and titanium dioxide $\left(\mathrm{TiO}_{2}\right)$ are investigated, taking into consideration the complex interaction between the electrical conductivity of the base fluid and that of the nanoparticles. The governing nonlinear partial differential equations were transformed into ordinary differential equations using the similarity approach and solved numerically using the RungeKutta-Fehlberg method coupled with the shooting technique. The effects of pertinent parameters on velocity, temperature, skin friction and local Nusset number are investigated. The conclusions drawn from the analysis can be summarised as follows:

- The fluid velocity decreases with increase in both the magnetic field strength $H a$ and nanoparticle concentration $\phi$.

- Increasing the magnetic field strength $H a$, Eckert number $E c$, Biot number $B i$ and nanoparticle concentration $\phi$ leads to an increase in the fluid temperature.

- The skin friction and rate of heat transfer at the plate surface increase with increase in nanoparticle concentration $\phi$.

- An increase in magnetic field strength $H a$ leads to an increase in the skin friction and a decrease in the rate of heat transfer. 
From the application point of view, the cooling effect on the plate surface is maximised by reducing the fluid flow velocity, enhancing the rate of heat transfer at the plate surface as well as minimising the skin friction at the plate surface. From the results obtained, this is achieved by employing $\mathrm{TiO}_{2}-\mathrm{EG}$ nanofluid as a coolant under the influence of a magnetic field. The interaction between the magnetic field and the fluid velocity results in the Lorentz force which impedes the fluid flow. It is evident from the above findings that the present study has numerous industrial, engineering and bio-medical applications such as heat transfer applications: industrial cooling, smart fluids; nanofluid coolant: vehicle cooling, electronics cooling; medical applications: magnetic drug targeting and nanocryosurgery.

\section{Acknowledgements}

The author would like to thank the reviewers for their valuable comments and suggestions.

Received: 29 December 2015 Accepted: 29 May 2016

Published online: 21 June 2016

\section{References}

1. Choi SUS (1995) Enhancing thermal conductivity of fluids with nanoparticles. In: Siginer DA, Wang HP (eds) Developments and applications of non-Newtonian flows, FED-vol 231/MD(66). ASME, New York, NY, USA, pp 99-105

2. Choi SUS (2009) Nanofluids: from vision to reality through research. J Heat Transf 131(3):1-9

3. Yu W, France DM, Routbort $J$, Choi SUS (2008) Review and comparison of nanofluid thermal conductivity and heat transfer enhancements. Heat Transf Eng 29(5):432-460

4. Tyler T, Shenderova O, Cunningham G, Walsh J, Drobnik J, McGuire G (2006) Thermal transport properties of diamond-based nanofluids and nanocomposites. Diam Relat Mater 15(11-12):2078-2081

5. Das SR, Choi SUS, Patel HE (2006) Heat transfer in nanofluids-a review. Heat Transf Eng 27(10):3-19

6. Liu M, Lin MC, Huang I, Wang C (2005) Enhancement of thermal conductivity with carbon nanotube for nanofluids. Int Commun Heat Mass 32(9):1202-1210

7. Makinde OD, Mutuku WN (2014) Hydromagnetic thermal boundary layer of nanofluids over a convectively heated flat plate with viscous dissipation and ohmic heating. UPB Sci Bull Ser A 76(2):181-192

8. Mutuku WN, Makinde OD (2014) On hydromagnetic boundary layer flow of nanofluids over a permeable moving surface with Newtonian heating. Lat Am Appl Res 44(1):57-62

9. Kaufui VW, Omar DL (2010) Applications of nanofluids: current and future. Adv Mech Eng. doi:10.1155/2010/519659

10. Singh D, Toutbort J, Chen G (2006) Heavy vehicle systems optimization merit review and peer evaluation. Annual Report, Argonne National Laboratory

11. Wang XQ, Mujumdar AS (2007) Heat transfer characteristics of nanofluids: a review. Int J Therm Sci 46:1-19

12. Das SK, Choi SUS, Patel HE (2006) Heat transfer in nanofluids-a review. Heat Transf Eng 27(10):3-19

13. Nguyen CT, Roy G, Gauthier C, Galanis N (2007) Heat transfer enhancement using $\mathrm{Al}_{2} \mathrm{O}_{3}$ water nanofluid for an electronic liquid cooling system. Appl Therm Eng 27(8-9):1501-1506

14. Leong KY, Saidur R, Kazi SN (2010) Performance investigation of an automotive car radiator operated with nanofluidbased coolants (nanofluid as a coolant in a radiator). Appl Therm Eng 30:2685-2692

15. Eastman JA, Choi SUS, Li S, Yu W, Thompson $\amalg$ (2001) Anomalously increased effective thermal conductivities of ethylene glycol-based nanofluids containing copper nanoparticles. Appl Phys Lett 78(6):718-720

16. Kwak K, Chongyoup K (2005) Viscosity and thermal conductivity of copper oxide nanofluid dispersed in ethylene glycol. Korea-Aust Rheol J 17(2):35-40

17. Pastoriza-Gallego M, Lugo L, Legido J, Piñeiro M (2011) Thermal conductivity and viscosity measurements of ethylene glycol-based $\mathrm{Al}_{2} \mathrm{O}_{3}$ nanofluids. Nanoscale Res Lett 6(221):1-11

18. Chen H, Ding Y, Lapkin A, Fan X (2009) Rheological behaviour of ethylene glycol-titanate nanotube nanofluids. J Nanopart Res 11(6):1513-1520

19. Reddy M, Chandra S, Rao VV, Reddy B, Chandra M, Sarada SN, Ramesh L (2012) Thermal conductivity measurements of ethylene glycol water based $\mathrm{TiO}_{2}$ nanofluids. Nanosci Nanotechnol Lett 4(1):105-109

20. Mutuku-Njane WN, Makinde OD (2014) MHD nanofluid flow over a permeable vertical plate with convective heating. J Comput Theor Nanosci 11:1-9

21. Heck A (2003) Introduction to maple, 3rd edn. Springer, Berlin

22. Makinde OD, Khan WA, Khan ZH (2013) Buoyancy effects on MHD stagnation point flow and heat transfer of a nanofluid past a convectively heated stretching/shrinking sheet. Int J Heat Mass Transf 62:526-533

23. Kuznetsov AV, Nield DA (2010) Natural convective boundary-layer flow of a nanofluid past a vertical plate. Int J Therm Sci 49:243-247

24. Ahmed SE, Mahdy A (2012) Natural convection flow and heat transfer enhancement of a nanofluid past a truncated cone with magnetic field effect. World J Mech 2:272-279 